Review Article

\title{
A Review on the Development and Properties of Continuous Fiber/epoxy/aluminum Hybrid Composites for Aircraft Structures
}

\author{
Edson Cocchieri Botelho ${ }^{\mathrm{a}, \mathrm{b}} *$, Rogério Almeida Silva ${ }^{\mathrm{c}, \mathrm{d}}$, \\ Luiz Cláudio Pardinia, Mirabel Cerqueira Rezende ${ }^{\text {a }}$ \\ ${ }^{a}$ Divisão de Materiais, Instituto de Aeronáutica e Espaço, CTA, \\ São José dos Campos, São Paulo, Brazil \\ ${ }^{b}$ Fatigue and Aeronautic Material Research Group, \\ Department of Material and Technology, UNESP, Guaratinguetá, São Paulo, Brazil \\ ${ }^{c}$ Departamento de Engenharia Mecânica e Aeronáutica, ITA, CTA, \\ São José dos Campos, 12228-904 São Paulo, Brazil \\ ${ }^{d}$ Empresa Brasileira de Aeronáutica - EMBRAER, \\ São José dos Campos, 12228-904 São Paulo, Brazil
}

Received: July 17, 2005; Revised: June 8, 2006

\begin{abstract}
Weight reduction and improved damage tolerance characteristics were the prime drivers to develop new family of materials for the aerospace/aeronautical industry. Aiming this objective, a new lightweight Fiber/Metal Laminate (FML) has been developed. The combination of metal and polymer composite laminates can create a synergistic effect on many properties. The mechanical properties of FML shows improvements over the properties of both aluminum alloys and composite materials individually. Due to their excellent properties, FML are being used as fuselage skin structures of the next generation commercial aircrafts. One of the advantages of FML when compared with conventional carbon fiber/epoxy composites is the low moisture absorption. The moisture absorption in FML composites is slower when compared with polymer composites, even under the relatively harsh conditions, due to the barrier of the aluminum outer layers. Due to this favorable atmosphere, recently big companies such as EMBRAER, Aerospatiale, Boing, Airbus, and so one, starting to work with this kind of materials as an alternative to save money and to guarantee the security of their aircrafts.
\end{abstract}

Keywords: fiber metal laminate, mechanical properties, composite materials

\section{Introduction}

Composite materials have been subject of permanent interest of various specialists during the last decades. Firstly, military applications in the aircraft industry triggered off the commercial use of composites after the Second World War. The innovations in the composite area have allowed significant weight reduction in structural design. Composites offer many advantages when compared to metal alloys, especially where high strength and stiffness to weigh ratio is concerned, excellent fatigue properties and corrosion resistance. On the other hand, they can present some disadvantages such as low fracture toughness and moisture absorption ${ }^{1-11}$.

Developments in continuous fiber reinforcement resulted in a large variety of fibers having a wide variety of mechanical properties. The high stiffness of carbon fibers, for instance, allows for extremely efficient crack bridging and therefore very low crack growth rates which leads to fatigue resistance ${ }^{12-17}$. During the last decades, efforts were concentrated in the development of fatigue resistant materials, which would keep low weight and good mechanical properties.

In 1982 the first commercial product under the trade name Arall (Aramid Reinforced Aluminum Laminates) was launched by ALCOA. The trades Arall 1 and Arall 2 were standardized. Arall 1 is a variant with aluminum 7075 layers and Arall 2 uses aluminum 2024 layers and it was in the as-cured condition ${ }^{15}$. The most successful product in this field was obtained at Delft University of Technology (Nether- lands), with the development of fiber-metal laminates (FML) using aramid, aluminum 7475-T761 and epoxy resin ${ }^{15,18,19}$. The metal layer in the composite is very favorable for the impact property improvements ${ }^{15}$. A patent on Glare (GLAss REinforced) was filed by AKZO in 1987. A partnership between AKZO and ALCOA started to operate in 1991 to produce and commercialize Glare ${ }^{15}$.

Nowadays, Glare materials are commercialized in six different standard grades (Table 1). They are all based on unidirectional glass fibers embedded with epoxy adhesive resulting in prepregs with a nominal fiber volume fraction of $60 \%$. During fabrication of composites the prepregs are laid-up in different fiber orientations between aluminum alloy sheets, resulting in different standard Glare grades as depicted in Figure $1^{15,20-28}$.

For the Glare 1, Glare 2, Glare 4 and Glare 5 the composite laminae, i.e. the fiber/resin layer, are stacked symmetrically. In the case of Glare 3 composite, the composite lamina have a cross-ply fiber layer stacked to the nearest outer aluminum layer of the laminate, in relation to the rolling direction of the aluminum. For the Glare 6 composite, the composite layers are stacked at $+45^{\circ}$ and $-45^{\circ 15}$. Table 1 shows these grades, including the most important material advantages.

A laminate coding system is used to specify laminates from the Table 1. For instance: 
Table 1. Standard Glare grades ${ }^{15}$.

\begin{tabular}{|c|c|c|c|c|}
\hline Glare grade & Sub & Al sheet thickness (mm) & $\begin{array}{c}\text { Prepreg orientation in } \\
\text { each fiber layer }\end{array}$ & $\begin{array}{c}\text { Main beneficial } \\
\text { characteristics }\end{array}$ \\
\hline Glare 1 & - & $0.3-0.4(7475-\mathrm{T} 761)$ & $0 / 0$ & Fatigue, strength, yield stress \\
\hline \multirow[t]{2}{*}{ Glare 2} & Glare $2 \mathrm{~A}$ & $0.2-0.5(2024-\mathrm{T} 3)$ & $0 / 0$ & fatigue, strength \\
\hline & Glare 2B & $0.2-0.5(2024-\mathrm{T} 3)$ & $90 / 90$ & fatigue, strength \\
\hline Glare 3 & - & $0.2-0.5(2024-\mathrm{T} 3)$ & $0 / 90$ & fatigue, impact \\
\hline \multirow[t]{2}{*}{ Glare 4} & Glare 4A & $0.2-0.5(2024-\mathrm{T} 3)$ & $0 / 90 / 0$ & Fatigue, strength, in $0^{\circ}$ direction \\
\hline & Glare 4B & $0.2-0.5(2024-\mathrm{T} 3)$ & $90 / 0 / 90$ & Fatigue, strength, in $90^{\circ}$ direction \\
\hline Glare 5 & - & $0.2-0.5(2024-\mathrm{T} 3)$ & 0/90/90/0 & Shear, off-axis properties \\
\hline \multirow[t]{2}{*}{ Glare 6} & Glare 6A & $0.2-0.5(2024-\mathrm{T} 3)$ & $+45 /-45$ & Shear, off-axis properties \\
\hline & Glare 6B & $0.2-0.5(2024-\mathrm{T} 3)$ & $-45 /+45$ & \\
\hline
\end{tabular}

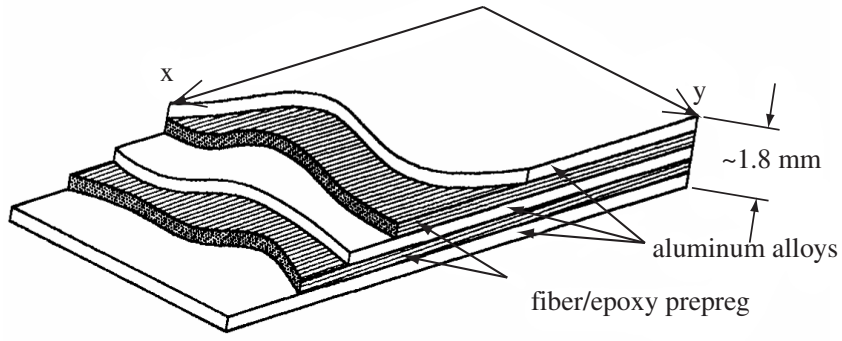

Figure 1. Configuration of continuous fiber/metal/epoxy hybrid composite (3/2 lay up).

Glare 2B-4/3-0.4, means a

- Glare laminate with fiber orientation according to the Glare 2B, as presented in Table 1;

- having 4 layers of aluminum and 3 fiber/epoxy composite layers; and

- each aluminum layer is $0.4 \mathrm{~mm}$ thick.

As for any other composite material, the properties of fiber/metal laminates depends strongly on the properties on the type of the reinforcing fibers. For instance, aramid-epoxy composites have good specific strength, specific modulus and high impact resistance, but they have poor compressive strength. Carbon/epoxy and glass/epoxy composites exhibit high specific modulus but relative low values of specific strength, strain to failure and impact resistance in relation to aramid/epoxy composites. Although not commercially available yet, carbon fiber/epoxy is tough to be used as an alternative adhesive layer to FML. These FML composites can be named CARAL (CArbon Reinforced Aluminum Laminates). In terms of fatigue, it was recognized that aramid fiber composites have better low-cycle fatigue performance but worse high-cycle fatigue performance than carbon fiber composites ${ }^{29-34}$. The combination of high stiffness and strength with good impact property gives to the carbon/aluminum laminates a great advantage for space applications. Other applications that can be envisaged for this laminate are impact absorbers for helicopter struts and aircraft seats ${ }^{15}$.

Studies addressing costs of FML showed that they are five to ten times more expensive per kilogram than a traditional aluminum alloy used in the aerospace field, but they can exhibit at least $20 \%$ weight savings in the role structure. So, airplane builders evaluated that the substitution of traditional aluminum by FML could be advantageous because their excellent mechanical properties ${ }^{15}$.

Nowadays, FML are being used in several applications such as: wing structures, fuselage and ballistic protection. The Figure 2 shows a FML composite application in the Airbus A380 airplane ${ }^{15}$.

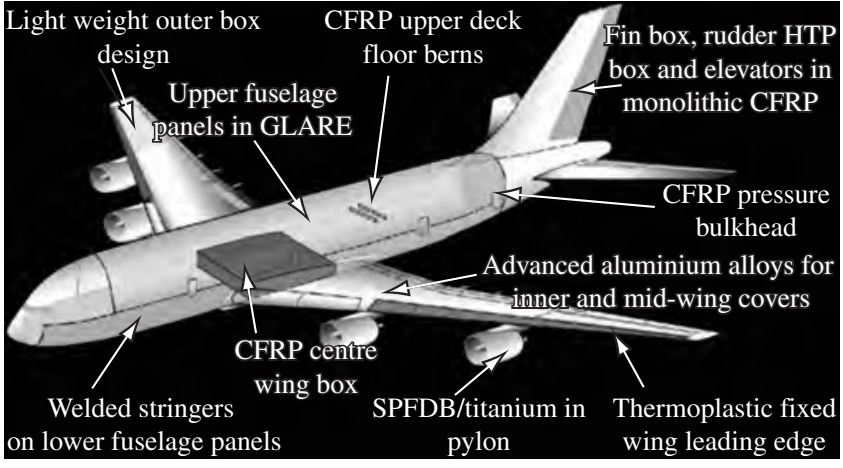

Figure 2. Metal/fiber applications in A380 airplane from Airbus ${ }^{15}$.

Several other aeronautical companies, such as Aeroespatiale, NASA, Bombadier and recently, EMBRAER, have interest in substitute the traditional aluminum components by FML composites.

The main purpose of this paper is to discuss properties and behavior of fiber/metal hybrid composite materials as an alternative for use in airplane structures.

\section{The Production of Metal/laminate Hybrid Composites}

The most common process used to produce FML laminates, as for polymeric composite materials, involves the use of autoclave processing f $^{75,35-39}$. The overall generic scenario for the production of FML composite aerospace components involves about five major activities ${ }^{7}$ :

1. Preparation of tools and materials. During this step, the aluminum layer surfaces are pre-treated by chromic acid or phosphoric acid, in order to improve the bond between the adhesive system and the used aluminum alloy;

2. Material deposition, including cutting, lay-up (as depicted in Figure 2) and debunking;

3. Cure preparation, including the tool cleaning and the part transferring in some cases, and the vacuum bag preparation in all cases;

4. Cure, including the flow-consolidation process, the chemical curing reactions, as well as the bond between fiber/metal layers; and

5. Inspection, usually by ultrasound, $\mathrm{X}$ ray, visual techniques and mechanical tests.

The cure preparation step involves primarily the bagging of the part and the placement of many ancillary materials. The common cure preparation arrangement, including the part, the tool, the bagging and the ancillary materials are shown in Figure 3. The function of these 


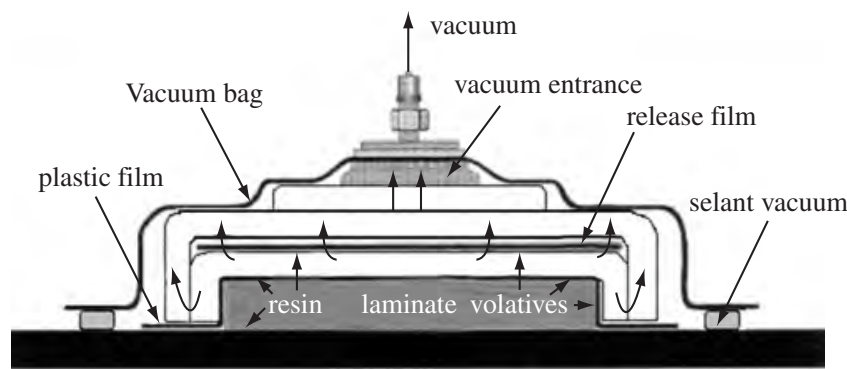

Figure 3. Schematic representation of vacuum bag system.

various components are: vacuum bag (the envelope parts and the tools for vacuum can be made by nylons, polymer blends, some metals or silicone rubbers); plastic and release films (release composite from tools, can be made by fluorinated ethylene propylene; halohydrocarbon polymers; PTFE; polyimides; polyamides or polytetramethylene terephthalamide) and bleeder (absorbs the excess of resin, it can be made by woven fabrics, felts ${ }^{7}$.

During the autoclave processing it is necessary a previous knowledge involving the temperature and the pressure requirements, for the composite layer consolidation and cure. In general, the FML are processed up to $120{ }^{\circ} \mathrm{C}$ in order to avoid damages in the aluminum 2024-T3 alloys. At this temperature the resin viscosity is reduced and flows. Adequate temperature levels to be used during the consolidation process can be determined by using thermal and rheological techniques ${ }^{40-52}$. Pressure is needed to press and to consolidate the plies and suppress voids. Thermal and rheological techniques are appropriate to study the events that takes place in the composite layer, and so optimized curing cycles can be obtained, as exemplified in Figure 4.

\section{Mechanical Properties}

The mechanical properties of FML have been object of investigation in many research institutes, universities and aircraft industries. Tension, compression, shear and impact are the main tests under use for screening properties of FML ${ }^{15}$.

In particular, the impact properties of several Glare materials are better than those of aluminum, while the impact behavior of glass fiber composites are significantly lower than the aluminum. Impacted Glare laminates presents a dent on the surface, similarly to aluminum ${ }^{15}$. The damage tolerance of Glare also is better when compared to aluminum and polymer laminates. Fatigue damage in many adjacent riveted holes causes significant strength loss for the 2024-T3 alloys while the strength reduction for Glare is less significant ${ }^{15}$.

Simple composite micromechanics calculations can be used to compare the elastic properties of polymer composites and fiber/metal laminates. Theoretical modelling uses a self consistent model (FGM code) to calculate data for composite elastic constants and so a comparison with experimental data can be maid $^{53}$. In the self consistent model, it is considered that spatially oriented composite rods, which represents fibre bundle orientation, are transversely isotropic. The local stiffness tensor for each of these rods is calculated and rotated in space to fit the global composite axes (Figure 5). The global stiffness tensors of all the composite rods are then superimposed with respect to their relative volume fraction to form the composite stiffness tensor ${ }^{53}$.

In order to obtain the elastic properties the FGM code attend the Equation 1:

$$
\mathrm{C}_{22}=2 \mathrm{C}_{44}+\mathrm{C}_{23}
$$

where $\mathrm{C}_{\mathrm{ij}}=$ stiffness tensor.

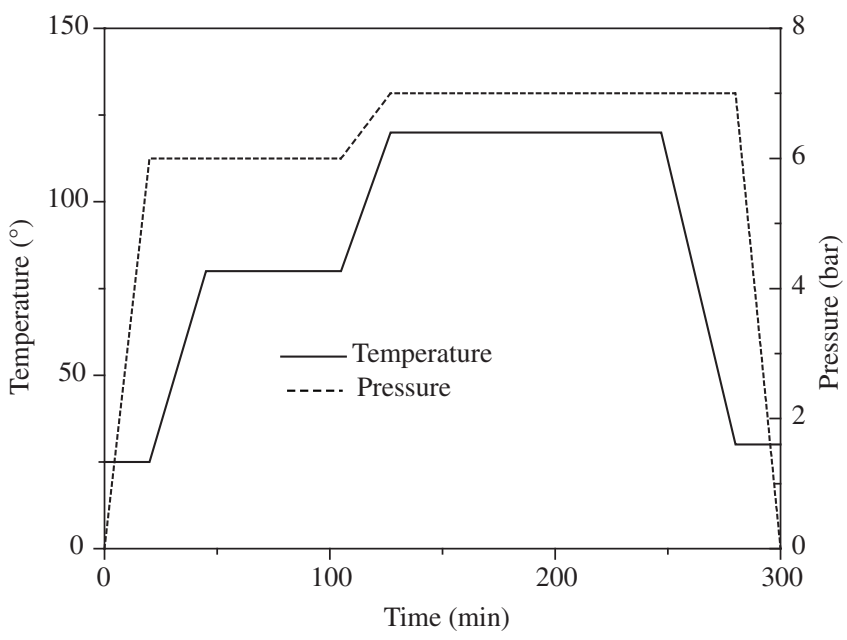

Figure 4. Typical autoclave cure cycle for metal/fiber laminates and thermosetting composites.

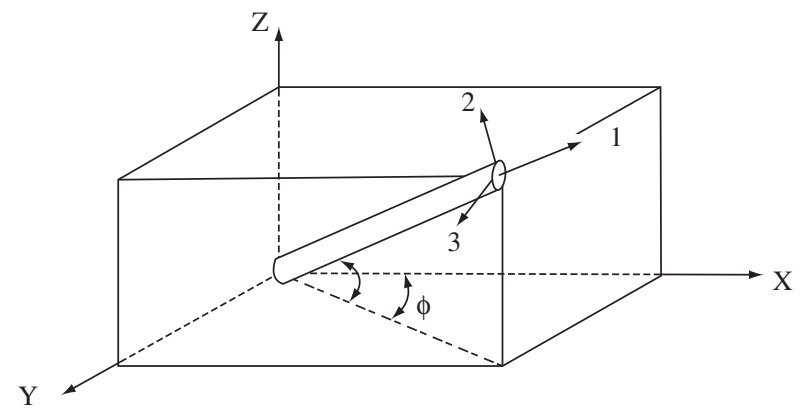

Figure 5. Determination of direction cosines for a fiber spatially inclined.

If properties in the transverse plane are independent of direction (transverse isotropy), $v_{13}=v_{12}$ and $G_{31}=G_{23}$. However, $v_{12} \neq v_{21}$ and $v_{13} \neq v_{31}$. Because of isotropy in the transverse plane, $E_{22}, v_{23}$ and $G_{23}$ are related by Equation 2:

$$
G_{23}=\frac{E_{22}}{2\left(1+\nu_{23}\right)}
$$

where: $\mathrm{E}_{23}, \mathrm{G}_{23}$ and $v_{23}$ are the Young's modulus, shear modulus and Poisson's ratio (in the plane of transverse isotropy), respectively ${ }^{53,54}$.

The transformation of the matrix local stiffness to the matrix global stiffness can be obtained by:

$$
\mathrm{C}_{\text {global }}=\mathrm{T}_{\sigma}^{-1} \mathrm{C}_{\text {local }} \mathrm{T}_{\varepsilon}
$$

where: $\mathrm{C}_{\text {global }}$ and $\mathrm{C}_{\text {local }}$ are the global and local matrix stiffness, respectively, and $\mathrm{T}_{\sigma}$ and $\mathrm{T}_{\varepsilon}$ are the stress and strain transformation of the matrices, successively.

The matrix and fiber properties used in order to calculate the mechanical properties of composite materials, are shown in Table 2:

For the FML composite, however, the rule of mixtures (Equation 4 and Table 2) was used for the calculation of elastic properties, since the FGM model is not suitable for modelling properties of such hybrid materials.

$$
E_{\text {al/fiber }}=E_{\mathrm{al}} V_{\mathrm{al}}+E_{\mathrm{c}}\left(1-\mathrm{V}_{\mathrm{al}}\right)
$$

where: $\mathrm{E}_{\mathrm{al} / \mathrm{carbon}}, \mathrm{E}_{\mathrm{al}}$ and $\mathrm{E}_{\mathrm{c}}$ are $\mathrm{E}_{\mathrm{x}}$ of metal/fiber laminate, aluminum and fiber/epoxy composites, respectively. 
Results for elastic constants for CARAL and GLARE laminates compared to the mother materials are shown in Table 3 (laminate orientated in $0 / 90^{\circ}$ ). In this case, $\mathrm{E}_{\mathrm{x}}$ for CARAL and GLARE laminates are 72 and 55 GPa respectively, as shown in Table 3.

If fiber reinforcement laminae direction is changed in relation to the main axis, changes in the FML elastic constants can be calculated.
Figure 6 show the variation of elastic constants in composites with a laminae in $0^{\circ}$ and a second laminae varying from 0 up to $90^{\circ}$. At any fiber composite laminae orientation the Glare composite, Figure $6 \mathrm{a}$, has better elastic properties than the glass fiber/epoxy composite. Lower differences are found when the laminae is at $0^{\circ}, \sim 45 \mathrm{GPa}$ and $\sim 59 \mathrm{GPa}$ for the glass fiber/epoxy composite and Glare composite,

Table 2. Parameters used in the FGM program and the mixtures rules.

\begin{tabular}{|c|c|c|c|c|c|}
\hline material & Fraction content $(\%)$ & $\mathrm{E}_{\mathrm{x}}(\mathrm{GPa})$ & $\mathrm{E}_{\mathrm{y}}(\mathrm{GPa})$ & $\mathrm{G}_{12}(\mathrm{GPa})$ & $v_{12}$ \\
\hline Epoxy & $40^{*}$ & 5.00 & 5.00 & 1.85 & 0.30 \\
\hline Carbon fiber & $60 *$ & 220 & 20.0 & 15.0 & 0.20 \\
\hline Glass fiber & $60 *$ & 72.0 & 72.0 & 28.8 & 0.14 \\
\hline Aluminum 2024-T3 & $\sim 57$ & 72.4 & 72.4 & 28.0 & 0.33 \\
\hline
\end{tabular}

* value used only in the polymeric composite.

Table 3. Theoretical Engineering Constants.

\begin{tabular}{lccccccc}
\hline \multicolumn{1}{c}{ Specimen } & Fiber content $(\%)$ & $\mathrm{Al}$ content $(\%)$ & $\mathrm{E}_{\mathrm{x}}(\mathrm{GPa})$ & $\mathrm{E}_{\mathrm{y}}(\mathrm{GPa})$ & $\mathrm{G}_{12}(\mathrm{GPa})$ & $\mathrm{G}_{13}(\mathrm{GPa})$ & $\mathrm{v}_{12}$ \\
\hline Carbon /epoxy & 60.0 & 0.00 & 71.3 & 71.3 & 3.86 & 3.39 & 0.03 \\
Glass/epoxy & 60.0 & 0.00 & 30.6 & 30.6 & 6.03 & 5.72 & 0.15 \\
Aluminum* & 0.00 & 100 & 72.4 & 72.4 & 28.0 & 28.0 & 0.33 \\
Al/carbon/epoxy & 25.3 & 57.9 & 71.9 & 71.9 & 17.8 & 17.6 & 0.20 \\
Al/glass/epoxy & 25.3 & 57.9 & 54.8 & 54.8 & 18.8 & 18.6 & 0.25 \\
\hline
\end{tabular}

* obtained in the literature ${ }^{15}$.
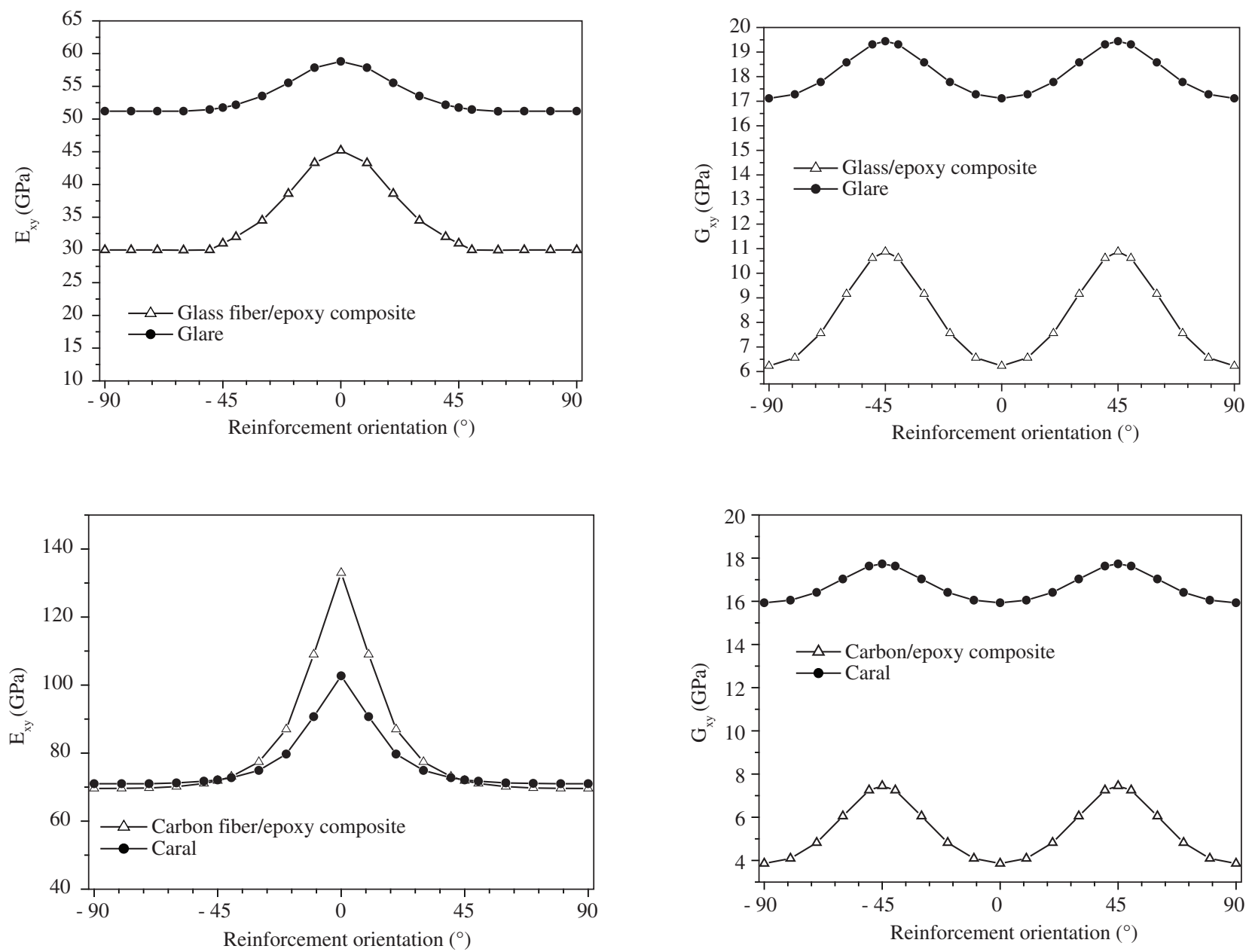

Figure 6. Mechanical properties of fiber/epoxy laminate, Glare and Caral with the reinforcement in different orientations. 
respectively. The $\mathrm{G}$ modulus for Glare composite, at any fiber composite laminae orientation, is almost twice the modulus of the glass fiber/epoxy composite, due to the contribution of aluminum $\mathrm{G}$ modulus ( $28 \mathrm{GPa})$. It has to be pointed out that glass fiber is isotropic in properties (Table 2).

The E modulus for carbon fiber/epoxy composite at $0^{\circ}$ orientation is higher than for Caral composite ( $0^{\circ}$ fiber composite laminae), $\sim 130 \mathrm{GPa}$ and $\sim 100 \mathrm{GPa}$ respectively, due to the high carbon fiber E modulus (220 GPa). On the other hand, the off-axis E modulus for carbon fiber/epoxy composites having fiber orientation higher than $10^{\circ}$ are lower than for Caral composites. This is due to the carbon fiber properties, which is transversely isotropic, as shown in Table 2. As for the Glare composite, Caral exhibits higher G modulus compared to carbon fiber/epoxy composite due to aluminum contribution, attaining levels of the Glare composites ( $18 \mathrm{GPa}$ ). Previous works reported that experimental $\mathrm{E}$ modulus, measured by vibration tests, are close to the ones calculated theoretically in the present work ${ }^{55,56}$.

\subsection{Tensile behavior}

Tensile properties of FML are influenced by their individual components. So, stress/strain behavior of FML exhibits well defined elastic response from the composite laminae and aluminum up to $2.0 \%$ strain, and load bearing capability, associated with the aluminum stress/strain plastic region, responsible for the toughness and notch sensitivity. Typical stress/strain curves for FML and their mother materials are shown in Figure 7. There is a combination of high stiffness and strength from the composite layer and good impact properties from aluminum, resulting in a great performance for space applications ${ }^{15,37,38,43,54}$. In FML composites the interface bond between the carbon fiber/epoxy laminae and the aluminum plays an important role in the transfer of stresses in the composite, as for the fiber/matrix interface ${ }^{15}$. Table 4 shows results for the tensile strength of carbon fiber/epoxy, glass fiber/epoxy, Glare and Caral composites.

The tensile strength for glass fiber and carbon fiber are $3.45 \mathrm{GPa}$ and $3.65 \mathrm{GPa}$, respectively ${ }^{15}$. So, at a same fiber volume fraction

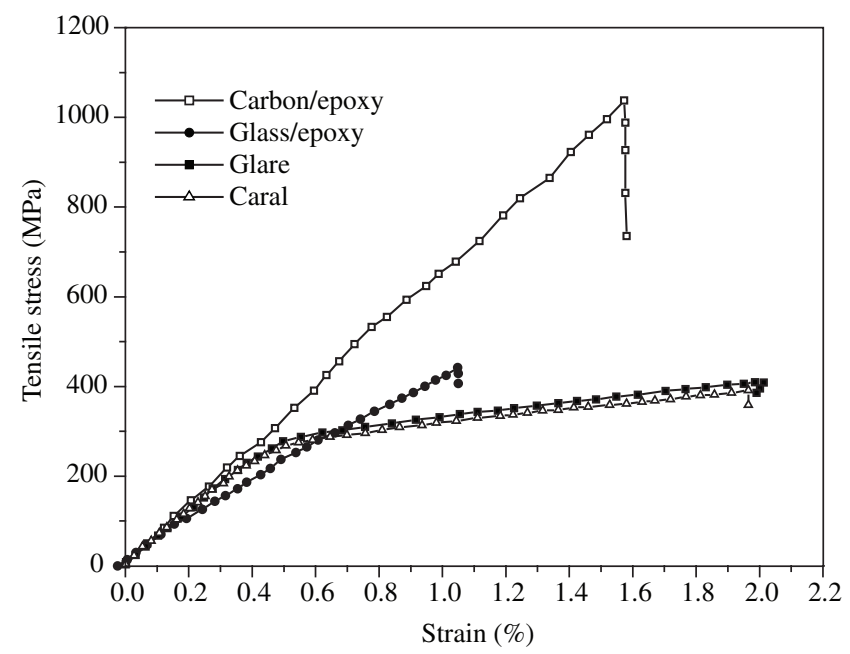

Figure 7. Tensile behavior of the laminates studied.

Table 4. Tensile values obtained by the specimens studied.

\begin{tabular}{cccc}
\hline Specimen & $\sigma_{\text {wlt }}(\mathrm{MPa})$ & $\varepsilon(\%)$ & $\mathrm{E}(\mathrm{GPa})$ \\
\hline $\mathrm{CF} / \mathrm{E}$ & $1160 \pm 37$ & $1.74 \pm 0.06$ & $67.2 \pm 4$ \\
GF/E & $570 \pm 17$ & $1.18 \pm 0.04$ & $26.7 \pm 2$ \\
Glare & $380 \pm 23$ & $1.9 \pm 0.1$ & $55.3 \pm 2$ \\
Caral & $420 \pm 29$ & $1.6 \pm 0.2$ & $58.9 \pm 2$ \\
\hline
\end{tabular}

the CF/E composite tensile strength would be higher than GF/E composite tensile strength. Tensile strength of individual fibers and the composite tensile strength explains diferences in the tensile strength for CF/E and GF/E composites, shown in Table 4. This, in turn, has and influence in the tensile strength for Glare $(\sim 380 \mathrm{MPa})$ composite and Caral composites ( $420 \mathrm{MPa})$ composite. Ultimate failure strength for Glare and Caral occurrs at strains $\sim 1.9 \%$ and $\sim 1.6 \%$, respectively.

Theoretical and experimental E modulus (Tables 3 and 4) agreed well for $\mathrm{CF} / \mathrm{E}$ composite ( $4 \%$ lower for the experimental value), although for GF/E composite the experimental E modulus is 13\% lower than the theoretical value. Equations for composite micromechanics calculations do not take into account the bond interface effects or void presence. For unidirectional composite, the axial E modulus is mainly fiber dominated being less sensitive to interfacial adhesion effects. In the case of Glare and Caral composites, results shown in Table 4, the measured tensile strength is $\sim 24$ and $\sim 18 \%$, respectively, lower than the calculated value by the micromechanical approach. Besides the fiber/matrix interface effects in polymer composite layer, the interface bond between the metal layer and the composite laminae in the FML composite can lead to differences in experimental results and theoretical calculations using the micromechanical approach.

\subsection{Compressive behavior}

The compressive strength of composites dependents on the way the loading is applied. In particular, the axial compressive strength for unidirectional polymer composites is mainly controlled by the buckling modes of the fibers ${ }^{57}$.

Figure 8 shows typical compressive stress as a function of strain for Glare and Caral laminates Results for compressive strength of polymer composites (CF/E and GF/E) and the hybrid composites (Glare and Caral) are shown in Table 5 (according with DIN EN 285043). Results shown in Table 5 follows trends found for tensile strength considering the same composites (Table 4), i.e, Glare laminates ex-

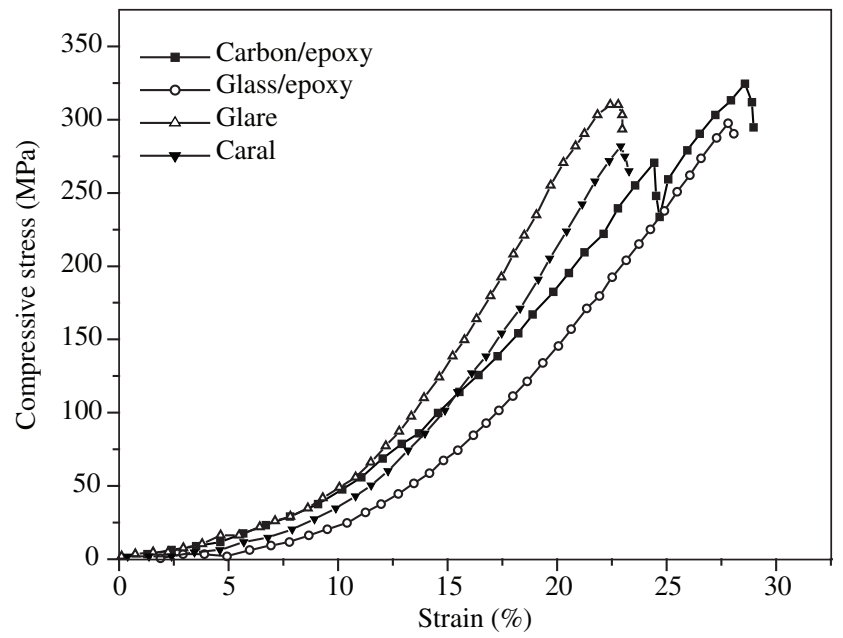

Figure 8. Compressive behavior of the laminates studied.

Table 5. Compressive behavior of the specimens studied.

\begin{tabular}{lll}
\hline \multicolumn{1}{c}{ Specimen } & $\sigma(\mathrm{MPa})$ & Strain $(\%)$ \\
\hline Carbon fiber/epoxy & $390 \pm 24$ & $25.1 \pm 0.6$ \\
Glass fiber/epoxy & $300 \pm 26$ & $25.3 \pm 0.9$ \\
Glare & $310 \pm 16$ & $19.9 \pm 1.2$ \\
Caral & $319 \pm 12$ & $22.5 \pm 0.3$ \\
\hline
\end{tabular}


hibited the lowest strength value among all investigated composites. This behavior happened due to differences in stiffness between carbon fiber and glass fiber. The ultimate compressive strength for Glare and Caral occurred at a strain of $\sim 19.9$ and $22.5 \%$, respectively.

In compression, the shape of the curve has additional meaning, because it shows if there is an opportunity for modifying the materials' properties by means of cold working on aluminum, such as stretching (which for FMLs also means modifying the internal stress-state) ${ }^{15,37}$.

It may be seen in Table 5 that the compressive strength value was higher for carbon fiber/epoxy composite, as expected. Therefore, the fiber/metal laminates presented the lowest values, due to the weak interface between the composite layer and the aluminum alloy.

The development of damage microstructure within fiber/metal laminates during compression is investigated mainly by scanning electron microscopy technique. SEM micrographs (Figure 9) revealed that the damage in the FML laminates under compression load occurred mainly between the reinforcement and the fiber. Figures 9a and $9 \mathrm{c}$ show a bucking failure of the aluminum layer which is associated to the damage in the polymeric composite laminae. This is the reason for the low compressive strength found for fiber/metal laminates when compared to polymeric composites.

The Figures $9 \mathrm{~b}$ and $9 \mathrm{~d}$ shows delamination failures under compressive load which are mainly located inside the composite laminae. The investigation of damage sources (inside of polymeric composite) led to detection of zones which contain broken and crushed fibers which underwent some local rotations.

\subsection{Shear strength behavior}

Shear behavior of composite materials is a matrix dominated property. Interlaminar shear strength is governed by the adhesion between fibers and matrix. Additionally, in FML the interface bond layer between aluminum and the composite laminae can play the role. The determination of shear properties of materials in general, and advanced composites in particular, is not an easy task. Different devices and test methods has been proposed in the literature in order to measured and study the shearing properties since the early ages of composite materials ${ }^{15}$. Many of them are criticized because one of the main difficulties in measuring shear properties for these materials is to induce a pure shear stress state in the gauge section of a constant magnitude. This is a special concern for composites because they exhibit high anisotropy and structural heterogeneity. In general, the ideal shear test must be simple enough to perform, require small and easily fabricated specimens, enable measuring of very reproducible values for both shear modulus and shear strength at simple data procedure ${ }^{15,37}$.

For a long time the short beam shear test has been used to measure the apparent interlaminar shear strength of a composite materials. The short beam shear method gives quality control information and it is not suitable for design specifications. Despite this restriction, data generated from this test method is still used to obtain design allowables, primarily because of the lack of any alternative test methods for measuring interlaminar strength ${ }^{15,37}$.

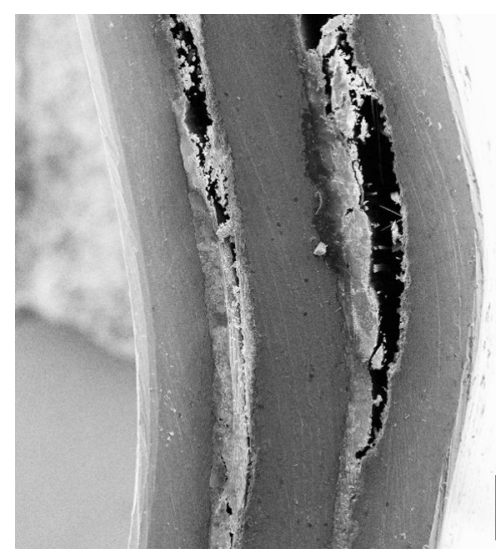

(a)

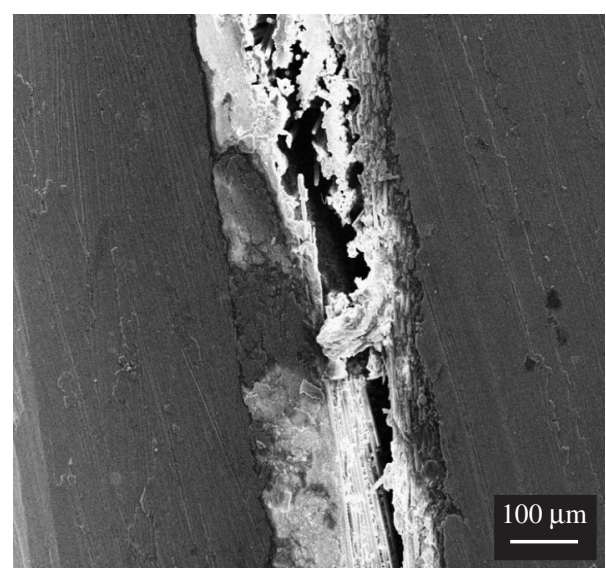

(b)

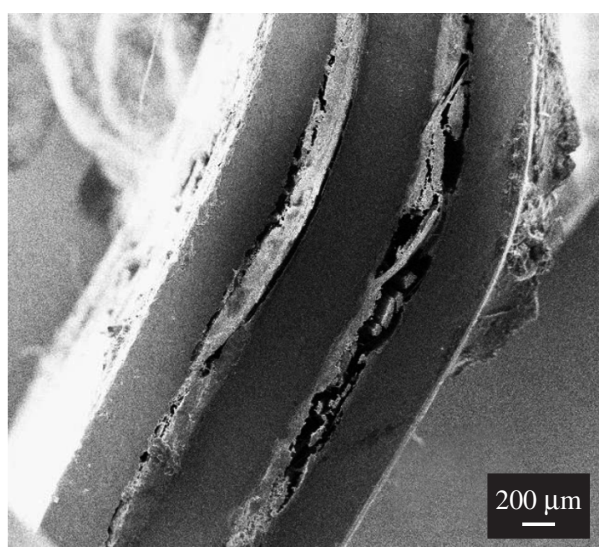

(c)

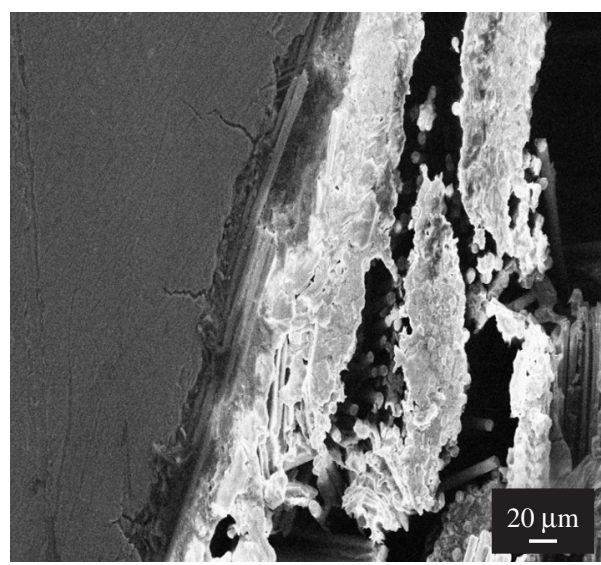

(d)

Figure 9. Microstructure of the compressive behavior of the laminates studied: a, b) Glare; and c, d) Caral. 
Table 6 presents the interlaminar shear strength (ILSS) results for polymer composite materials and for FML composites. The interlaminar shear strength for $\mathrm{CF} / \mathrm{E}$ and $\mathrm{GF} / \mathrm{E}$ composites is more than twice the value for FML composites (Caral and Glare), $~ 85 \mathrm{MPa}$ and $\sim 40 \mathrm{MPa}$, respectively. The polymer interface layer between the aluminum foil and the composite laminae is not strong enough to keep the interlaminar shear strength at the level of polymer composites.

\subsection{Damping behavior}

Elastic modulus of material can be determined by semi-static tests, and they are usually destructive. On the other hand, dynamic mechanical tests, are an interesting alternative for elastic property determination, offering the advantage of being non-destructive. Nowadays, various experimental methods are potentially applicable to determine dynamic mechanical properties of composites (free vibration, rotating-beam deflection, forced vibration response, continuous wave or pulse propagation technique) have been used and reviewed ${ }^{58-60}$.

Among the vibration tests, one of the most used is the free beam vibration. The measurement principle consists of recording the vibration decay of a rectangular, or beam, plate excited by a controlled mechanism to identify the elastic and damping properties of the material under test. The damping amplitudes are measured by accelerometers as a function of time. The free vibration method results in a logaritmic damping $(\Delta)$ given by the Equation $5^{61-63}$.

$$
\Delta=\ln \left(\frac{\delta_{1}}{\delta_{2}}\right)=\frac{1}{n} \ln \left(\frac{\delta_{1}}{\delta_{2}}\right)
$$

where $\delta_{1}$ and $\delta_{2}$ are the first and the end amplitude

Analogaly, the damping factor can be obtained by:

$$
\zeta=\sqrt{\frac{\Delta^{2}}{\Delta^{2}+4 \pi^{2}}}
$$

The storage modulus (E') can be obtained according to Equation $7^{69-71}$.

$$
E^{\prime}=\frac{4 \pi^{2} f^{2}}{3 I} \cdot\left[M+\frac{33}{140} m\right] \cdot L^{3} \cdot\left[1+\frac{\Delta^{2}}{4 \pi^{2}}\right]
$$

where: $E^{\prime}=$ elastic modulus; $\mathrm{f}=$ natural frequency; $\mathrm{I}=$ inertial moment; $\mathrm{M}=$ accelerometer weight $\mathrm{m}=$ specimen weight $\mathrm{L}=$ specimen lenght and $\Delta=$ logaritmic damping.

Table 6. Interlaminar shear strength values for carbon fiber/epoxy composites.

\begin{tabular}{lc}
\hline \multicolumn{1}{c}{ Specimen } & $\tau(\mathrm{MPa})$ \\
\hline Carbon fiber/epoxy & $84.5 \pm 2.1$ \\
Glass fiber/epoxy & $87.2 \pm 1.1$ \\
Caral & $38.1 \pm 1.2$ \\
Glare & $40.2 \pm 1.7$ \\
\hline
\end{tabular}

Using damping factor and E', can be calculated E" (viscous modulus) and $\tan \delta$ (loss factor) according to Equations 8 and 9:

$\tan \delta=\frac{1 n\left(\delta_{1} / \delta_{2}\right)}{n \pi}$

and

$$
\tan \delta=\frac{E^{\prime \prime}}{E^{\prime}}
$$

Figure 10 represents a typical vibration damping representative curve of the Glare. The curve shows an exponential decay of maximum peak amplitudes as a function of time.

The storage modulus (E') is calculated by Equation 7, and Table 7 shows the results. By using the rule of mixtures, the calculated elastic modulus for Caral composite is $2.3 \%$ higher than the experimental result (Table 7). The experimental modulus values when compared with the theoretical values of polymeric composites results in a decrease of $16 \%$ and $3 \%$, for carbon fiber/epoxy and glass fiber/epoxi composites, respectively. The experimental modulus values of aluminum 2024-T3, Caral and Glare composites result in a decrease of $5 \%, 10 \%$ and $9 \%$, respectively.

Elastic modulus of composites obtained by experimental measurements differs from values obtained from the theoretical calculations (micromechanics approach), because ideal bonding between fiber/ matrix interface, perfect alignment of fibers and absence of voids and other defects are considered in the last. For the FML composites there is an additional factor related to the influence of surface treatment on the aluminum foil, which is not considered also in the theoretical calculations ${ }^{64-66}$. The result of the elastic modulus for the aluminum 2024 alloy, Table 7, shows a good agreement between the value found in the literature and the experimental value ${ }^{67}$.

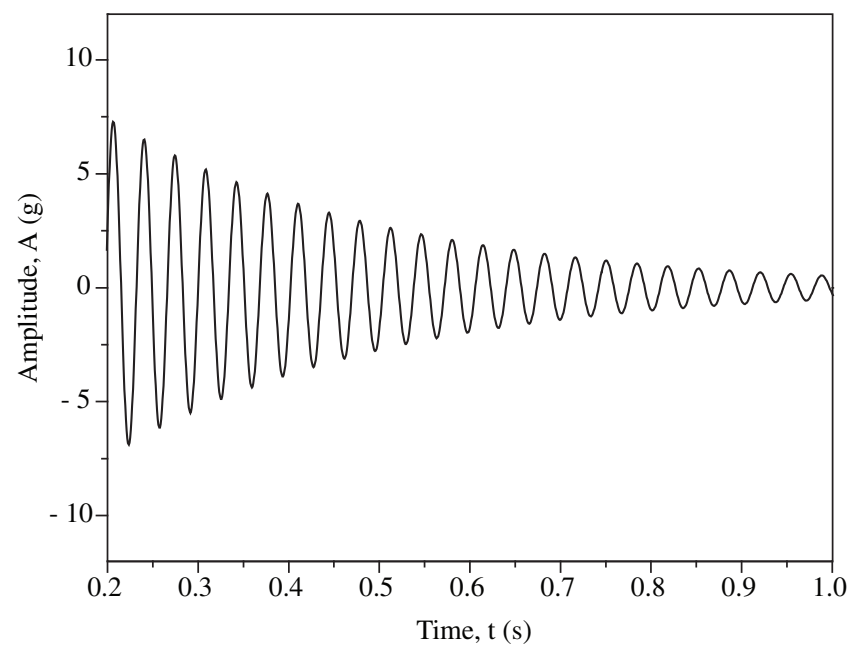

Figure 10. Vibration damping curves from Glare.

Table 7. Values of viscoelastic properties obtained by vibration test.

\begin{tabular}{lcccc}
\hline \multicolumn{1}{c}{ Specimen } & Theoretical E' $(\mathrm{MPa})$ & Experimental E' $(\mathrm{GPa})$ & $\tan \delta$ & E’ $^{\prime}(\mathrm{GPa})$ \\
\hline Carbon fiber/epoxy & 71.3 & $63.9 \pm 5.4$ & $4.32 \times 10^{-2}$ & 2.42 \\
Glass fiber/epoxy & 35.0 & $32.2 \pm 2.8$ & $3.14 \times 10^{-2}$ & 1.02 \\
Caral & 71.9 & $60.9 \pm 4.2$ & $2.26 \times 10^{-2}$ & 1.37 \\
Glare & 54.8 & $50.1 \pm 3.8$ & $2.94 \times 10^{-2}$ & 1.46 \\
Aluminum & 70.2 & $66.1 \pm 4.7$ & $1.24 \times 10^{-2}$ & 0.82 \\
\hline
\end{tabular}


The loss modulus is proportional to the $E^{\prime}$ and $\zeta$ values, and it is related to the energy dissipation mechanisms in materials. In hybrid composites, such as Glare and Caral, the loss modulus is also a combination of energy dissipation mechanisms from the composite laminae, metal foil and the interface between them. So, in this case the energy dissipation due to interfacial adhesion can play the role.

Table 7 presents also the E" values for carbon fiber/epoxy, glass fiber/epoxy, aluminum 2024 alloy, Caral and Glare composites. It can be observed in Table 7, the E" values for Carbon fiber/epoxy and glass fiber/epoxy composites were $2.42 \mathrm{MPa}$ and $1.02 \mathrm{MPa}$, respectively. Thus, the Glass fiber/epoxy dissipates less energy per cycle of damping than the CF-E composite. Table 7 shows that the E" value for aluminum 2024-T3 (0.82 MPa) is lower than GF-E and CF-E composites. In metals a large part of the loss is hysteretic, caused by dislocation movement ${ }^{15}$.

For Glare composite it was found an E" value of $1.46 \mathrm{MPa}$, which is lower than for Caral $(44 \%)$. The damping of composites is mainly controlled by E' of reinforcement fiber and the interface between the reinforcement and matrix. Therefore, in hybrid composites such as metal/fiber composites, damping is controlled by E' of metal and reinforcement, associated with the surface treatment of the aluminum foil.

The values of $\tan \delta$ for all specimens studied can be found in Table 7. The $\tan \delta$ value for the Carbon fiber/epoxy is the highest among all the specimens, because it dissipates more energy per cycle of vibration. The values found by Glare and Caral were intermadiate when compared with their individual constituents.

\section{Environmental Effects on Fiber/metal laminates}

The combination of moisture and metals is known to lead to corrosion. Pure aluminum is a very reactive metal, which quickly builds up an oxide layer on its surface. In order to eliminate or decrease the corrosion phenomenon, a protective layer can be applied on the material surface. This can be made by anodisation, applying a clad layer of pure aluminum, or by painting ${ }^{15,68-73}$.

The influence of moisture in polymer is also expressive. Like any other polymers, epoxies can absorb moisture when exposed to humid environments. This takes place through of a diffusion process, in which water molecules are transported from areas with high concentration to areas with lower moisture concentration ${ }^{15,68-73}$. Fick's law describes the most types of moisture diffusion ${ }^{68-73}$ :

$$
\frac{\partial c}{\partial t}=D_{x} \frac{\partial^{2} c}{\partial x^{2}}+D_{y} \frac{\partial^{2} c}{\partial y^{2}}+D_{z} \frac{\partial^{2} c}{\partial z^{2}}
$$

with: $\mathrm{c}=$ free water molecule concentration

$\mathrm{D}_{\mathrm{x} y \mathrm{z}}=$ diffusion coefficient in $\mathrm{x}, \mathrm{y}$ and $\mathrm{z}$-direction respectively.

When the material is exposed to a constant humidity environment, the water diffusion process continues until the saturation of the material is reached. The concentration level, where saturation is completed is known as the equilibrium moisture concentration. The rate of moisture absorption into the composite laminate can be measured by performing weight measurements during the exposure period. The mass increase is assumed as the amount of moisture absorbed by the composite.

The moisture absorption in FML composites is slower than polymer composites, even under the relatively harsh conditions, due to the barrier of the aluminum outer layers, as show Figure 11.

The bond between the fiber and the epoxy matrix plays a very important role in the stress transfer in a composite. Unfortunately, the fiber/matrix interfaces are sensitive to the chemical effects of moisture. The moisture adsorption in composites is not uniform throughout the material, and induces strong matrix plasticization ${ }^{15}$. In the case of FML composites, the bond between the aluminum layer and the polymer composite laminae can also be a target for moisture degradation. If the composite interfaces are attacked by moisture an influence on the shear properties can be expected, as showed in Figure 12. The plasticization of resin matrix and composite related interfaces leads to a decrease in the interlaminar shear strength values due to hygrothermal conditioning ${ }^{15}$.

\section{The next Generation of Fiber Metal Laminate}

Materials can be combined to form new hybrid ones having enhanced properties. However, there are several factors that should be considered when designing a new hybrid material, such as: extreme internal stress, galvanic corrosion, voids and volatile contents.

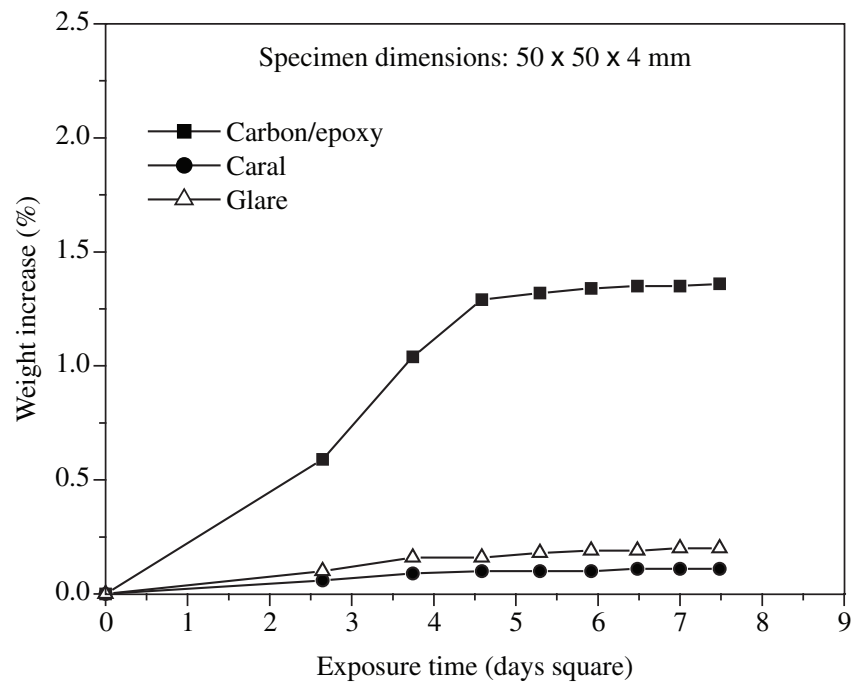

Figure 11. Mass gain of FML and polymeric composite specimens exposed at $80{ }^{\circ} \mathrm{C}$ and $90 \% \mathrm{RH}$.

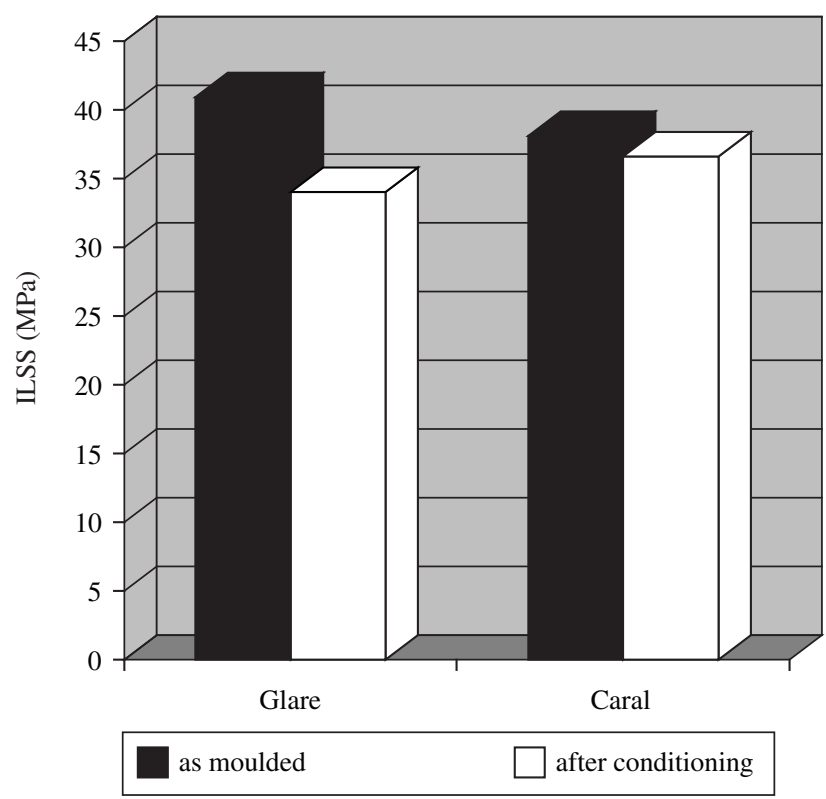

Figure 12. ILSS strength of Glare and Caral (CFML). 
Moreover technological difficulties, availability and costs are also important issues. In general, materials will not be used when the price is exceptionally high or the manufacture technologies are not feasible. Glare has been developed for relatively cold structures. Nowadays, Glare laminate production involves epoxy resin cured up to $120^{\circ} \mathrm{C}$, 2024-T3 aluminum and glass fibers. Using epoxy resin system with a $177^{\circ} \mathrm{C}$ curing epoxy and the aluminum 2024-T81, a laminate can created which can be used up to $180{ }^{\circ} \mathrm{C}$ due to this metal support this temperature. This laminate can be used in parts of airplane when it is necessary the use of artifacts above $120{ }^{\circ} \mathrm{C}^{15}$.

New metal/fiber hybrids composites, besides Glare and Arall, are nowadays under investigation for use as structural components, such as aluminum/boron/epoxy, titanium/carbon fiber/epoxy, etc ${ }^{15}$. Caral, for instance, can be included in the next generation category of hybrid fiber material. Titanium seems to be the next hybrid fiber metal laminate to be introduced in the market since it has a high stiffness, high yield strength, good fatigue and good impact properties at room and elevated temperatures ${ }^{15}$.

Other issued such as bonding properties of fibers and metal sheet materials, temperature influences, sensitivity to moisture, flow properties of the adhesive and glass transition temperatures affect properties of FML composites. Other resin matrices, besides epoxy, and a variety of fiber reinforcements are also being considered for use in FML composites ${ }^{15}$.

The works involving FML in Brazil were initiated in 1997 by Universidade Federal do Rio de Janeiro (UFRJ). The work started at COPPE-UFRJ on the Arall FML composite and the emphasis was placed on the characterization of these materials by single edge bend tests and microstructural characterization.

Later in 2002, the Materials Division (AMR) from the Instituto de Aeronáutica e Espaço (IAE/CTA) in São José dos Campos began to work with Glare and Caral materials. Emphasis of the work in CTA since then was on characterization FML composites by various tests including damping behavior, tensile, compression, Iosipescu and three bending point tests. Nowadays environmental effects on Glare are also being under study. For these studies Empresa Brasileira de Aeronáutica (EMBRAER) supply the FML composite laminates.

Other universities, such as USP and UNESP, are starting research activities on FML laminates in other important areas that lack knowledge for these materials, such as fatigue resistance.

\section{Acknowledgments}

The authors acknowledge the financial support received from FAPESP under grant 02/01288-3 and 03/04240-4. The authors are indebted to Dr. José Maria F. Marlet from EMBRAER.

\section{References}

1. Botelho EC, Rezende MC. O uso de Compósitos Estruturais na Indústria Aeroespacial. Polímeros: Ciência e Tecnologia. 2000; 10(2):E4-E10.

2. Zhang PQ, Ruan JH, Li WZ. Influence of Some Factors on the Damping Property of Fiber-Reinforced Epoxy Composites at Low Temperature. Cryogenics. 2001; 41:245-253.

3. Botelho EC, Rezende MC, Nogueira CL. Monitoring of Nylon 6.6/Carbon Fiber Composites Processing by X-ray Diffraction and Thermal Analysis. Journal of Applied Polymer Science. 2002; 86:3114-3121.

4. Botelho EC, Scherbakoff N, Rezende MC, Kawamoto AM, Sciamareli J. Synthesis of Polyamide $6 / 6$ by Interfacial Polycondensation with the Simultaneous Impregnation of Carbon Fiber. Macromolecules. 2001; 34:(10):3367-3374.

5. Bhatnagar T, Ramakrishnan N, Kaik NK, Komanduri R. On the Machining of Fiber Reinforced Plastic (FRP) Composite Laminates. International Journal Mach. Tools Manufacture. 1995; 35(5):701-708.
6. Potter K. Introduction to Composite Products, First edition, Chapman \& Hall, London, UK, 1997.

7. Gutowski TG. Advanced Composites Manufacturing, First edition, John Wiley \& Sons, New York, USA, 1997.

8. Matthews FL, Rawlings RD. Composite Materials: Engineering and Science, second edition Woodhead Publishing Limited, Cambridge, England, 1999.

9. Pardini LC. Tecnologia de Fabricação de Pré-Impregnados Para Compósitos Estruturais Utilizados na Indústria Aeronáutica. Polímeros: Ciência e Tecnologia. 2000; 10(2):100-109.

10. Hou M, Ye L, Lee HJ, Mai YW. Manufacture of a Carbon-Fabric-Reinforced Polyetherimide (CF/PEI) Composite Material. Composites: Science and Technology. 1998; 58(2):181-190.

11. Hillermeier RW, Seferis JC. Interlayer Toughening of Resin Transfer Molding Composites. Composites Part A. 2001; 32:721-729.

12. St John NA, Brown JR. Flexural and Interlaminar Shear Properties of Glass-Reinforced Phenolic Composites. Composites Part A. 1998; 29:939346

13. Callus PJ, Mouritz AP, Bannister MK, Leong KH. Tensile Properties and Failure Mechanisms of 3D woven GRP composites. Composites Part A. $1277 ; 30: 1277-1286$

14. Degallaix G, Hassaïni D, Vittecoq E. Cyclic Shearing Behaviour of a Unidirectional Glass/Epoxy Composite. International Journal of Fatigue. 2002; 24:319-326.

15. Vlot A, Gunnink JW. Fibre Metal Laminates, Kluwer Academic Publishers, Dordrecht, The Netherlands, 2001

16. Tarnopol'skii YM, Arnautov AK, Kulakov VL. Methods of Determination on Shear Properties of Textile Composites. Composites Part A. 1999; 30:879-886.

17. Rikards R. Interlaminar Fracture Behaviour of Laminated Composites. Computers \& Structures. 2000; 76:11-18.

18. Catrodeza EM. Desenvolvimento e Avaliação de Técnicas Experimentais para o Estudo da Mecânica da Fratura de Laminados Fibra-Metal, $\mathrm{PhD}$ thesis, Universidade Federal do Rio de Janeiro, Rio de Janeiro, 2002.

19. Dymácek P. Fiber-Metal Laminates Steel-C/Epoxy. PhD thesis, Institute of Aerospace Engineering, Faculty of Mechanical Engineering of Brno University of Technology, Czech Republic, 2001.

20. Kawai M, Hachinohe A, Takumida K, Kawase Y. Off-axis fatigue behaviour and its damage mechanics modelling for unidirectional fibre-metal hybrid composite: GLARE 2. Composites Part A. 2001; 32:13-19.

21. Soprano A, Apicella A, D'Antonio L, Scettino F. Application of Durability Analysis to Glare Aeronautical Components. International Journal of Fatigue. 1996; 18(4):265-272.

22. Unal O, Barnard DJ, Anderson IE. A Shear test Method to Measure Shear Strength of Metallic Materials and Solder Joints using Small Specimens. Scripta Materialia. 1999; 40(3):271-279.

23. Chiang MYM, He J. An analytical assessment of using the losipescu shear test for hybrid composites. Composites Part B. 2002; 33(6):461-468.

24. Kawai M, Morishita M, Tomura S, Takumida K. Inelastic Behavior and Strength of Fiber-Metal Hybrid Composite: Glare. International Journal Mechanical Science. 1998; 40(2-3):183-190.

25. Naboulsi S, Mall S. Thermal Effects on Adhesively Bonded Composite Repair of Cracked Aluminum Panels. Theoretical and Applied Fracture Mechanics. 1997; 26:1-8.

26. Asnafi N, Langstedt G, Andersson C-H, Östergren N, Hakansson T. A New Lightweight Metal-Composite-Metal Panel for Applications in the Automotive and Other Industries. Thin-Walled Structures. 2000; 36:289296.

27. Asundi A, Choi AYN. Fiber Metal Laminates: An Advanced Material for Future Aircraft. Journal of Materials Processing Technology. 1997; 63:384-389.

28. Wittenberg TC, Van Baten TJ, Boer A. Design of Fiber Metal Laminate Shear Panels for Ultra-High Capacity Aircraft. Aircraft Design. 2001; 4:99-106. 
29. Lin CT, Kao PW. Effect of fiber bridging on the fatigue crack propagation in carbon fiber-reinforced aluminum laminates. Materials Science \& Engineering A. 1995; 190:65-72.

30. Takamatsu T, Matsumura T, Ogura N, Shimokawa T, Kakuta Y. Fatigue Crack Growth Properties of a GLARE-3-5/4 fiber/metal laminate. Engineering Fracture Mechanics. 1999; 63:253-260.

31. Vogelesang LB, Vlot A. Development of Fibre Metal Laminates for Advanced Aerospace Structures. Journal of Materials Processing Technology. 2000; 103:1-8.

32. Castrodeza EM, Touça JMR, Ipiña, JEP, Bastian FL. Determination of CTODc in Fibre Metal Laminates by ASTM and Schwalbe Methods. Materials Research. 2002; 5(2)119-125.

33. Castrodeza EM, Ipiña JEP, Bastian FL. Experimental Techniques for Fracture Instability Toughness Determination of Unidirectional Fibre-Reinforced Metal Laminates. Fatigue \& Fracture of Engineering Materials. 2002; 25(11):999-1005.

34. Castrodeza EM, Yawny A, Ipiña JEP, Bastian FL. Fracture Micromechanisms of Fibre-Metal Laminates: In-Situ SEM Observations. Journal of Composite Materials. 2002; 36(4):387-400.

35. Botelho EB, Costa ML, Paiva JMF, Rezende MC. Avaliação Térmica e Reológica do Ciclo de Cura do Pré-Impregnado de Carbono/Epóxi. Polímeros: Ciência e Tecnologia. 2003; 13:188-199.

36. Costa ML. Efeito do Conteúdo de Vazios no Comportamento Mecânico de Compósitos Avançados Carbono/Epóxi e Carbono/Bismaleimida, $\mathrm{PhD}$ thesis, Instituto Tecnológico de Aeronáutica, São José dos Campos, Brazil, 2002.

37. Cândido GM. Influência do Condicionamento Ambiental na Resistência à Delaminação de Borda Livre em Compósitos Avançados, $\mathrm{PhD}$ thesis, Instituto Tecnológico de Aeronáutica, São José dos Campos, Brazil, 2001.

38. Cândido GM, Almeida SFM. Effect of the free edge finishing on the tensile strength of carbon/epoxy laminates. Composites Structures. 1993; 25: 287-300.

39. Schwartz MM. Composite Materials - Properties, Nondestructive Testing and Repair, vol. I, Prentice Hall Inc, New Jersey, USA, 1997.

40. Mayer C, Wang X, Neitzel M. Macro-and micro-impregnation phenomena in continuous manufacturing of fabric reinforced thermoplastic composites. Composites Part A. 1998; 29:783-794.

41. Botelho EC, Rezende MC., Yamagishi DS, Marlet JMF. Processing of the Obtaining of Structural Reinforcement Impregnated with Polyamide 6/6 obtained by Interfacial Polymerization, Using a Reaction Injection Pultrusion System. Brazilian Patent, PI. 6561-7, 2001.

42. Botelho EC, Rezende MC, Scherbakoff N. Study of Polyamide 6/6 Synthesis Carried Out by Interfacial Polymerization on Carbon Fibre. Polymer International. 2002. 51:1261-1273.

43. Botelho EC. Compósitos aeronáuticos processados a partir de fibras de carbono impregnadas com poliamida $6 / 6$ via processo de polimerização interfacial. PhD thesis, Instituto Tecnológico de Aeronáutica, São José dos Campos, São Paulo Brazil, 2002.

44. Botelho EC, Scherbakoff N, Rezende MC, Rheological Studies Applied in the Processing and Characterization of Carbon/Carbon Composites. Journal of Advanced Materials. 2001; 33(4):44-57.

45. Botelho EC, Scherbakoff N, Rezende MC. Rheological Analysis of the Phenolic and Furfuryl Resins used in the Carbon Materials Processing. Materials Research. 2000; 3(2):19-26.

46. Botelho EC, Scherbakoff N, Rezende MC. Estabelecimento de Parâmetros Reológicos na Obtenção de Compósitos Carbono/Fenólica. Polímeros: Ciência e Tecnologia. 1999; 1:59-65.

47. Lee C-L, Wei K-H. Effect of material and process variables on the performance of resin-transfer-molded epoxy fabric composites Journal of Applied Polymer Science. 2000; 77(10):2149-2161.

48. Hillermeier RW, Seferis JC. Interlayer Toughening of Resin Transfer Molding Composites. Composites Part A. 2001; 32:721-732.

49. Phillips R, Glauser T, Manson J-AE. Thermal Stability of PEEK/Carbon Fiber in Air and Its Influence on Cosolidation. Polymer Composites. 1997; 18(4):500-512.
50. Shim S-B, Seferis JC, Eom YS, Shim YT. Thermal characterization and comparison of structural prepregs with different cure temperatures. Thermochimica Acta. 1997; 291:73-80.

51. Wingard CD. Characterization of prepreg and cured epoxy/fiberglass composite material for use in advanced composite piping systems. Thermochimica Acta. 2000; 357-358:293-302.

52. Hayes BS, Gilbert EN, Seferis JC. Scaling complications of dual temperature cure resin prepreg systems in airplane part manufacture. Composites: Part A. 2000; 31(7)717-726.

53. Pastore CM, Gowayed YA. A Self-Consistent Fabric Geometry Model: Modification and Application of a Fabric Geometry Model to Predict the Elastic Properties of Textile Composites. Journal of Composites Technology \& Research. 1994. 16(1):32-45.

54. Zweben C, Hahn HT, Chou T-W. Mechanical Behavior and Properties of Composite Materials: volume 1. Delaware Composites Design Encyclopedia, Pennsylvania, USA, 1989.

55. Botelho EC, Silva RA, Pardini LC, Rezende MC. Evaluation of Adhesion of Continuous Fiber-Epoxy Composite/Aluminum Laminates. Journal of Adhesion Science and Technology. 2004; 18(15-16):1799-1812.

56. Botelho EC, Pardini LC, Rezende MC. Processing and Hygrothermal Effects on Viscoelastic Behavior of Glass Fiber/Epoxy Composites. Journal of Materials Science. 2005; 40:3615-3623.

57. Hull D, Clyne TW. An Introduction to Composite Materials. $2^{\text {nd }} \mathrm{ed}$. Cambridge University Press.1996.

58. Cerny M, Glogar P, Manocha LM. Resonant Frequency Study of Tensile and Shear Elasticity Moduli of Carbon Fibre Reinforced Composites (CFRC). Carbon. 2000; 38:2139-2148.

59. El-Mahdy TH, Gadelrab RM. Free Vibration of Unidirectional Fiber Reinforcement Composite Rotor. Journal of Sound and Vibration. 2000; 230:195-204.

60. Pritz T. Frequency Dependences of Complex Moduli and Complex Poisson's Ratio of Real Solid Materials. Journal of Sound and Vibration. 1998; 214(1):83-90.

61. Rao SS. Mechanical Vibrations. Addison Wesleg Publishing Co. New York, USA, 1990.

62. Roark RJ. Formulas for stress and strain. McGraw Hill, vol. 5, USA, 1976.

63. Dinarogonas AD. Vibration Engineering. West Publishing Co. New York, USA, 1976.

64. Kumar CS, Mayanna SM, Mahendra KN, Sharma AK, Rani RU. Studies on White Aanodizing on Aluminum alloy for Space Applications. Applied Surface Science. 1999; 51:280-293.

65. Zhan Z, Ma X, Sun Y, Xia L, Liu Q. The Mechanical Properties of an Aluminum Alloy by Plasma-Based Ion Implantation and Solution-Aging Treatment. Surface \& Coatings Technology. 2000; 128:256-264.

66. Proust G. Adhesion of Protective Coating Appliques on Contaminated Aluminum Surface. master degree dissertation, Drexel University, USA, 2001.

67. Metals Handbook-Properties and Selection: nonferrous alloys and pure metals, vol. 2, Ninth edition, ASM Handbook Committee, USA, 1979.

68. Sala G. Composites Part B. 2000; 31:357-364,

69. Dae W. et al. Equilibrium water uptake of epoxy/carbon fiber composites in hygrothermal environmental conditions. Journal of Composite Materials. 2001; 35:264-278.

70. $\mathrm{Hu} \mathrm{H}$, Sun $\mathrm{CT}$. The equilibrium of moisture and temperature in physical aging of polymeric composites. Journal of Composite Materials. 2003; 37(10):913-928.

71. De Wilde WP, Frolkovic P. The modelling of moisture absorption in epoxies: effects at the boundaries. Composites. 1994; 25(2):11-19.

72. Curtis PT, More BB. Composites. 1983; 14(3):120-128.

73. Lee BL, Holl MW. Effects of moisture and thermal cycling on in-plane shear properties of graphite fibre-reinforced cyanate ester resin composites. Composites-Part A. 1996; 27:1015-1022. 